\title{
The prediction of professional behaviour
}

\author{
David T Stern, ${ }^{1}$ Alice Z Frohna ${ }^{2} \&$ Larry D Gruppen ${ }^{2}$
}

OBJECTIVE The purpose of this study was to establish outcome measures for professionalism in medical students and to identify predictors of these outcomes.

DESIGN Retrospective cohort study.

SETTING A US medical school.

PARTICIPANTS All students entering in 1995 and graduating within 5 years.

MEASURES Outcome measures included review board identification of professionalism problems and clerkship evaluations for items pertaining to professionalism. Pre-clinical predictor variables included material from the admissions application, completion of required course evaluations, students' selfreporting of immunisation compliance, students' performance on standardised patient (SP) exercises, and students' self-assessed performance on SP exercises.

RESULTS The outcome measures of clerkship professionalism scores were found to be highly reliable (alpha 0.88-0.96). No data from the admissions material was found to be predictive of professional behaviour in the clinical years. Using multivariate regression, failing to complete required course evaluations $(\mathrm{B}=0.23)$ and failing to report immunisation compliance $(B=0.29)$ were significant predictors of unprofessional behaviour found by the review board in subsequent years. Immunisation noncompliance predicted low overall clerkship professional evaluation scores $(\mathrm{B}=-0.34)$. Student selfassessment accuracy (SP score minus self-assessed

${ }^{1}$ VA Ann Arbor Healthcare System, Division of General Medicine, Department of Internal Medicine, University of Michigan, Michigan, USA

${ }^{2}$ Department of Medical Education, University of Michigan, Michigan, USA

Correspondence: David T Stern MD, PhD, 300 North Ingalls Building, 7E10, Ann Arbor, Michigan 48109-0429, USA. Tel: 001734936 4787; Fax: 001734936 8944; E-mail: dstern@umich.edu score $)(\mathrm{B}=0.03)$ and immunisation non-compliance $(\mathrm{B}=0.54)$ predicted the internal medicine clerkship professionalism score.

CONCLUSIONS This study identifies a set of reliable, context-bound outcome measures in professionalism. Although we searched for predictors of behaviour in the admissions application and other domains commonly felt to be predictive of professionalism, we found significant predictors only in domains where students had had opportunities to demonstrate conscientious behaviour or humility in self-assessment.

KEYWORDS education, medical, undergraduate/ *standards; professional competence/*standards; educational measurement/standards; retrospective study; cohort study; United States.

Medical Education 2005; 39: 75-82

doi:10.1111/j.1365-2929.2004.02035.x

\section{INTRODUCTION}

'The most common criticism made at present by older practitioners is that young graduates have been taught a great deal about the mechanism of disease, but very little about the practice of medicine - or, to put it more bluntly, they are too "scientific" and do not know how to take care of patients.' Francis Peabody, $1927^{1}$

This comment is no less true today than it was 75 years ago, and reflects both the great success and a significant failure of medical education. Medical schools have an outstanding record for selecting students with the academic credentials to successfully proceed through the rigorous academic programme of medical education. The combination of examination scores and pre-medical school marks are strong predictors for successful completion of medical school courses and licensing examinations. ${ }^{2,3}$ 


\section{Overview}

\section{What is already known on this subject}

Professionalism is a key competency for doctors.

There are currently no tools with which to predict future professional behaviour.

\section{What this study adds}

Information available from admissions applications does not assist in the prediction of future professional behaviour.

Relative under-assessment of performance on a standardised patient exercise and evidence of conscientious behaviour early in medical school may predict an element of facultyperceived positive professional behaviour later in medical school.

\section{Suggestions for further research}

Systematic observation and assessment of a variety of professional behaviours by faculty and peers early in medical school might provide additional predictors of future professional behaviour.

Being a good doctor requires not only knowledge and skills, it also requires professional behaviour. ${ }^{4-6}$ However, professional behaviour implies more than being smart or technically expert. It is also involves more than the absence of unprofessional behaviour; it entails adopting and upholding a code of conduct. Although the knowledge and skills necessary to become a doctor have changed drastically over even the past generation, the professional behaviour expected of doctors has remained relatively constant for centuries. One might expect that with hundreds of excellent tests for knowledge and skills used in medical schools around the country, we must have developed some assessment of professional behaviour. Regrettably, there is not a single reliable and valid method available to predict the behaviours of our medical graduates in this domain. ${ }^{7,8}$

This lack of evaluation is not due to a lack of consensus on what constitutes professionalism. In fact, every major national commission set up to identify the traits of tomorrow's doctors emerges with a similar list of professional characteristics. ${ }^{5,9,10}$ The time and effort expended to create the documents, Tomorrow's Doctors ${ }^{11}$ and the European Federation of Internal Medicine/American Board of Internal Medicine Charter on Professionalism, ${ }^{12} \mathrm{dem}-$ onstrate our collective concern about the professional behaviour of doctors. But the students who graduate from our medical schools are taught and learn varying degrees of professional and unprofessional behaviour. ${ }^{13}$ Worst of all are the very rare cases of morally corrupt and frankly dangerous doctors who occasionally make national and international headlines. ${ }^{14,15}$

The most certain method of maintaining professional behaviour in doctors would be to ensure that only those students who are likely to behave professionally are admitted to medical school. When studied, the admissions process has been found to lack predictive power in areas outside academic performance. ${ }^{16}$ Although we can predict future performance in communication and moral reasoning skills as components of professionalism, ${ }^{17-20}$ these measurements have not been shown to correlate prospectively with global measures of professional behaviour.

One reason for this lack of predictive ability is that much of the published work on professionalism talks about professionalism as a set of values, virtues, or characteristics - overarching principles to which doctors are held. Recently, investigators have moved from this top-down, values-based approach to professionalism to a bottom-up, behaviour-based approach. ${ }^{7}$ If we are to identify and promote students for their professional behaviours, we must correlate observable events with reliable and valid outcomes.

The purpose of this study was to establish a reliable and valid outcome measure for professional behaviour in medical students, and to determine if any data from the admissions process or pre-clinical years of medical school could predict this professional behaviour.

\section{METHODS}

\section{Participants}

Students selected for this analysis were those who entered the University of Michigan Medical School in 
1995 ( $n=183$ ). Reasons for exclusion were failure to reach Year 3 of medical school in 3 or 4 years, due to taking medical scientist $(\mathrm{PhD})$ track courses $(n=6)$, death $(n=1)$, voluntary withdrawal $(n=3)$, extended leave $(n=2)$, dismissal for academic failure $(n=3)$. Also excluded were students on the combined BA/MD programme for whom no admissions variables were available for comparison $(n=15)$. The final sample included the 153 remaining students. All student data were collected, entered into a combined database, and names were deleted to maintain confidentiality. The research was considered 'exempt' under institutional policies for its use of non-identifiable research databases of student evaluation materials.

\section{Predictor data}

Predictor data came from 4 sources: the admissions packet, standardised patient evaluations, data on student participation in the course evaluation process, and immunisation compliance data (Table 1). From the admission packet, we extracted information on each student's family background, undergraduate experience and postgraduate experience. In addition, admission essays were required for all students under consideration in this study. These essays were read by 2 reviewers and evaluated as to whether they contained characteristics implying a facility for teamwork and interpersonal relations with patients, and tendencies towards duty and altruism.

Due to the very different contexts in which the admission essays and clerkship comments were written, additional qualities were gleaned from the essays which were judged to have some bearing on the students' future professional behaviour. These included a history of volunteering, personal experience with illness, a stated desire to work with underserved populations, and reliance on mentors. The 10 most frequent professionalism-themed

Table 1 Predictor variables

Variable

Admissions packet

Family background

Undergraduate

Admission essay themes

Postgraduate

Standardised patient interviews (SPIs)

Year 1 medical school

Year 2 medical school

Administrative data

\section{Description}

Father's and mother's amount of education

Whether father, mother or both were doctors

Year of high school graduation

College or university attended

Major

Extracurricular activities

Leadership positions in extracurricular activities

Membership on sports teams

Total grade point average

Science grade point average

Medical College Admissions Test (MCAT) Total Score

MCAT verbal, physical science and biological science (individually)

MCAT writing (converted to numerical score)

Advanced degrees

Postgraduate job or other experiences

SP medical interviewing (MI) score

Student-assessed MI SPI

MI self-assessment vector (SPI-student score)

SPI sexually transmitted disease (STD) interviewing score

Student-assessed STD SPI

STD self-assessment vector (SPI-student score)

Evaluation compliance

Immunisation compliance 
categories were included as predictor variables in our model.

Four standardised patient (SP) interviews are carried out by all medical students in the first 2 years of medical school. Two of these are primarily used for teaching physical examination and were excluded from analysis. The 2 remaining exercises were intended to assess content (ability to ask up to 25 specific questions) and generic communication skills. The first SP interview takes place in the first 2-4 months of medical school and involves a generic medical interview (MI); the second involves a sexually transmitted disease (STD) risk assessment, performed at the beginning of Year 2 of medical school. Standardised patients are trained to evaluate student communication skills on an 8-item, 5-point scale with behavioural anchors ( 1 is low on all scales). These items included 'establishing rapport', 'transition statements', 'non-verbal communication' and 'closing the interview.' Patients review videotapes of SPstudent interactions until they have achieved adequate reliability ( \pm 1 point on the 5 -point scale across all items). The sum of scores across each of these 8 items of communication skills forms the SP MI and STD score.

Prior to receiving feedback from the SP, students are asked to complete a self-evaluation form, identical to that of the SP (8 items, 5-point anchored scale). This form is used to generate discussion between SP and student following the exercise. The sum of student self-assessed performance on each of these exercises comprises the student-assessed SP score (MI and STD). The difference between the SP and student scores on each exercise comprises the self-assessment accuracy score (MI and STD).

The faculty requires that all students complete course evaluations. To minimise the student effort on this detailed exercise, a quarter of the class is expected to complete the evaluation in each quarter of the year. There is no consequence for students who do not complete these evaluations; however, compliance is tracked by the Office of Educational Research and Resources. Students are identified in this database as completing either all or none of their required course evaluations.

Students are also required to maintain adequate records of 4 immunisations (MMR, TB, hepatitis, varicella). Students report these to the Office of Student Affairs. Students in the research database were given a score of $0-4$ depending on which one(s) of these immunisations they had properly reported.

\section{Outcome variables}

The outcome variables were a continuous measure of professional behaviour as assessed by faculty and residents and a discrete measure of whether a student was identified in the proceedings of the academic review board for professional behaviour (Table 2).

\section{Clerkship outcome}

Of the 7 clerkships required for Year 3 medical students, we used internal medicine, obstetrics and gynaecology $(\mathrm{OB} / \mathrm{GYN})$, paediatrics and surgery for our first outcome measure. We focused on 3 questions that specifically pertained to professionalism and were exactly identical across these 4 clerkships. These questions inquired about students' interpersonal skills, professional relationships and communication skills. The number of raters varied widely among clerkships, and in some cases among clerkship sites. Obstetrics and gynaecology generally had the fewest ratings per student; the team met as a group and reached an agreement about each student's score. At the other sites and clerkships, there were up to 20 raters for each student.

Three of the clerkships $(\mathrm{OB} / \mathrm{GYN}$, paediatrics, surgery) used a standard evaluation form provided by the medical school. These forms had a rating scale of 1-6, with descriptive text at each anchor to guide the evaluators. Internal medicine used a similar, but updated form, with a rating scale of 1-9 and behavioural anchors. The 3 questions pertaining to professionalism, although scaled differently, were worded identically to the form used by the other clerkships. Internal reliability (alpha) coefficients for these scales ranged from 0.88 for the surgery clerkship evaluation forms to 0.96 for the internal

Table 2 Outcome measures

\section{Clerkship outcomes}

Interpersonal skills item (Average within and across all rotations)

Professional relations item (Average within across all rotations)

Communication skills item (Average within across all rotations)

Combined (3 above) item (Average within across all rotations)

Academic review Board Presence, absence of comments 
medicine evaluation forms. All scales were rightshifted, but the 9-point scale, in particular, demonstrated a normal distribution (mean $=6.9, \mathrm{SD}=0.7$, skew -0.04 , kurtosis $=-0.09$ ). The 6-point scales had means ranging from 4.8 to 5.5 and SDs ranging from 0.5 to 1.1. They were less normal than the 9point scales (skew $=-0.68$ to -1.55 , kurtosis $=-0.55$ to 3.52$)$. From the numerical data, we calculated a mean professional rating for each clerkship. The internal medicine scores were standardised to account for the different scales. Correlations between average clerkship scores ranged from low (surgery to paediatrics: Kendall tau $=0.04 ; 95 \%$ CI - 0.12-0.20) to moderate (paediatrics to OB/GYN: Kendall tau $=0.21 ; 95 \%$ CI $0.05-0.36$; surgery to $\mathrm{OB} / \mathrm{GYN}$ : Kendall tau $=0.23 ; 95 \%$ CI $0.07-0.38$; medicine to $\mathrm{OB} / \mathrm{GYN}$ : Kendall tau $=0.24 ; 95 \%$ CI $0.09-0.38$ ). We also averaged the mean professional ratings from the 4 clerkships into an overall professional rating for each student. These scores had a Cronbach alpha of 0.90 .

\section{Academic review board outcome}

Rarely, students are identified as having unprofessional behaviour worthy of sanction. Such students are identified by the clerkship directors, faculty or fellow students. All such concerns of significant magnitude are referred to the clinical academic review board. Comprised of deans, elected faculty, appointed faculty and students, this committee reviews and recommends remediation or dismissal for academic failures and behavioural problems. One of the investigators reviewed the minutes of this board for all index students, and transcribed minutes of the meeting for those students who were identified as having non-academic (grade-related) problems. Presence $(n=11)$ or absence $(n=142)$ in this database provided the data for this outcome measure.

\section{Data analysis}

All data were entered into a single database, with student identifiers eliminated. We ran a Kolmogorov-Smirnov test (with the Lilliefors correction) and verified that the continuous variables (except missing immunisations) met normality tests. The binary variables were treated as interval. Parametric and non-parametric correlations were used to evaluate the magnitude of association between each predictor and each outcome variable. Because of the large number of predictors and the intercorrelations among them, a series of forward stepwise regressions were performed for each of the outcome variables to identify the most efficient subset of predictors from each group. Correlations for the clerkship evaluation outcomes were only considered significant if they were consistent across more than 1 clerkship or in the overall clerkship evaluation score.

\section{RESULTS}

There were no consistent, significant correlations between any materials from the admissions packet and any of the outcomes of professional behaviour in Year 3 of medical school. None of the expected relationships were significant, including parental education level, age at entry to medical school, extracurricular activities, sports participation, or advanced degrees. None of the 10 most common admissions essay themes were significantly correlated with any outcome measure. As would be expected, measures of knowledge alone (Medical College Admissions Test (MCAT) scores and grade point averages) did not correlate with professionalism.

Univariate correlation models identified missing immunisations, missing evaluations, and self-assessment accuracy as significant predictors of professional behaviour in the clinical years (Table 3). Missing immunisations correlated with appearance before the academic review board, with lower mean clerkship ratings, and specifically with lower ratings on the internal medicine clerkship. Missing evaluations also correlated with appearance before the academic review board. Finally, the accuracy of the student's self-assessment of clinical skill, compared with the SP assessment, was inversely correlated with professionalism ratings in the internal medicine clerkship, indicating that students who underestimated their

Table 3 Correlations of pre-clinical predictor variables with clinical outcomes in professionalism

\begin{tabular}{|c|c|c|c|}
\hline & \multicolumn{2}{|l|}{ Academic } & $\begin{array}{l}\text { Internal } \\
\text { medicine }\end{array}$ \\
\hline & $\begin{array}{l}\text { Review } \\
\text { Board }\end{array}$ & $\begin{array}{l}\text { Clerkship } \\
\text { mean }\end{array}$ & $\begin{array}{l}\text { clerkship } \\
\text { mean }\end{array}$ \\
\hline $\begin{array}{l}\text { Missing } \\
\text { immunisations }\end{array}$ & $0.26^{*}$ & $-0.34 *$ & $-0.21 *$ \\
\hline $\begin{array}{l}\text { Missing } \\
\text { evaluations }\end{array}$ & $0.32 *$ & -0.08 & -0.05 \\
\hline $\begin{array}{l}\text { SPI self-assessment } \\
\text { accuracy }\end{array}$ & 0.08 & -0.09 & $-0.22 *$ \\
\hline
\end{tabular}


actual performance received higher (more positive) ratings and students who overestimated their performance received lower ratings.

Because of the high degree of intercorrelation among these independent variables, forward stepwise multivariate regressions were used to identify the most efficient subset of predictors. In the subsequent multivariate models, only immunisation non-compliance $(\mathrm{B}=0.23,95 \% \mathrm{CI} 0.06-0.41)$ and the failure to complete required evaluation forms in the first 2 years of medical school $(\mathrm{B}=0.29,95 \%$ CI $0.08-0.29)$ predicted discussion at the academic review board in Year 3 of medical school. These 2 predictors accounted for almost $14 \%$ of the variance in academic review board appearance (adjusted $\left.R^{2}=0.135\right)$. Immunisation non-compliance predicted low overall clerkship professional evaluation scores $(\mathrm{B}=-0.34,95 \% \mathrm{CI}-1.13$ to -0.38$)$, accounting for just over $10 \%$ of the variance in this outcome (adjusted $R^{2}=0.110$ ).

The self-assessment accuracy for the Year 1 medical interviewing evaluation (SP score minus self-assessed score $)(B=0.03,95 \% \mathrm{CI}-0.06$ to -0.001$)$ and immunisation non-compliance $(\mathrm{B}=0.54,95 \% \mathrm{CI}$ -1.08 to -0.001$)$ predicted the internal medicine professionalism score. These 2 predictors accounted for only $6 \%$ of the variance in these ratings (adjusted $\left.R^{2}=0.061\right)$.

\section{DISCUSSION}

The evaluation of professionalism is one of the greatest challenges in medical education today. This study identifies a set of reliable, context-bound outcome measures in professionalism, based on the evaluations of faculty and residents who work closely with medical students during Year 3 of medical school. Although we searched for predictors of behaviour in the admissions packet and other domains commonly felt to be predictive of professionalism, we found significant predictors only in domains where students had had opportunities to demonstrate conscientious behaviour or humility in self-assessment. These 2 behaviour-based domains are more specific and observable than the more abstract values and virtues outlined in oaths, declarations and codes of professionalism, and provide an early glimpse of how professional behaviour could be evaluated reliably in the future.

Prior work in the area of predicting professional behaviour has included studies where communica- tion skills and moral reasoning skills in the pre-clinical years predict communication skills and moral reasoning in later years of medical school. ${ }^{17-19}$ In fact, there is good evidence that formal educational programmes in moral reasoning can enhance this skill among students. ${ }^{20}$ However, these skills have not yet been consistently correlated with observed professional behaviour in a prospective study. While good communication skills and moral reasoning ability are likely necessary for professional behaviour, they are not sufficient. There are many examples in the public domain of individuals with outstanding communication and reasoning skills whose lapses in professional behaviour become fodder for national news and exposé.

Admissions committees are known for their ability to predict the future test-taking success of students with the use of admissions examination scores and grades. Admissions committees are also often charged with identifying students who have the 'motivation, character and personal fitness' necessary to become doctors. ${ }^{21}$ Great effort is expended by students in composing admissions essays, and great expense and effort is incurred by medical school faculty in the evaluation of admissions materials, interviews and committee meetings in order to identify such applicants. Despite efforts to detect the utility of these activities, the current study fails to confirm the usefulness of these efforts. This is consistent with other research identifying the lack of predictive ability of the admissions process for the selection of students who will demonstrate future professional behaviour. ${ }^{16}$ There are certainly other important functions of admissions committees ${ }^{22}$ and the current study cannot conclusively confirm or refute the effectiveness of the admissions process. Committees may have rejected applications from students who were more unfit for practice than those admitted, but until a study of medical school applicants is conducted, this question will remain unanswered.

This study identified 2 domains early in medical school that predict elements of professional behaviour in Year 3 of medical school. Conscientious behaviour, as measured by immunisation and course evaluation compliance in pre-clinical years, was found to be predictive of outcomes in professionalism in clinical settings. Doctors and residents appreciate clinical medical students who show up on time, provide complete patient evaluations, and work within the norms and expectations of medical students. In practice, doctors who keep good medical records, remain compulsive in their follow-up of patient data and follow the norms of the profession 
are likely to be seen by others as 'professional.' In a recent study, Wright and Tanner found that students who failed to provide a passport photograph at the start of their paediatric module were more likely to fail the end of year examinations. ${ }^{23}$ Identifying more such specific, quantitative measures of conscientious behaviour in residents and practising doctors may help to further objectify this element of professionalism.

While self-assessment of performance itself is relatively inaccurate compared to using a gold standard,$^{24,25}$ the relative over- or underestimation of performance is a significant predictor of professionalism in this study. Those students who underestimated their performance in the first few months of medical school were more likely to be identified by faculty and residents as behaving in a professional manner during the clinical phase 2 years later. Does this reflect the value of 'humility', which is seen as a virtue in most doctors? Further study of this dimension and its relationship to professional behaviour is warranted.

The findings in this study are limited by their retrospective nature and the identification of 1 class of medical students from 1 medical school. Prospective validation of these findings will be necessary, and will potentially diminish their correlation, particularly if students become aware that such variables are being observed for use as predictors of elements of professionalism. In the medical school class under study, there were no extensive notes or reports available from small group leaders, anatomy laboratory professors or other faculty, which might, in other institutions, provide an interesting source of information for the future professional behaviour of medical students. Developing methods for capturing and codifying the comments of such faculty are likely to provide additional predictors.

In addition, it would be simplistic to imply that the predictor behaviours identified in this study represent the full spectrum of what we expect from the fully competent professional doctor. There are many other dimensions of professional competence not measured in this study, ${ }^{4,5}$ including compassion, responsibility to patients and altruism, among others. In addition, there are many different perspectives on student professional behaviour which are promising, but which were not evaluated in this study, including patient evaluations, peer evaluations and psychometric assessments. ${ }^{7}$ The future identification of these critical elements from multiple perspectives is a challenge for further research.
The measurement and prediction of professionalism is not so subjective that we cannot develop a means to accurately measure and detect professional behaviours when they are present. In fact, there are a number of unique observations from faculty and administrators identified in this study that, when carefully coded, could begin to provide clues to the future professional behaviour of medical students. The predictors identified in this study are, like the outcomes, behaviour-based, as is consistent with current sentiment among medical educators that the assessment of achievement in medical school and residency should be outcome-based. ${ }^{4,5,11}$ The dimensions of professionalism that these predictors reflect (conscientious behaviour and self-assessment accuracy) are more context-bound and concrete than the more generic values we include in our definitions of professionalism. There are likely to be many more such predictors and identifying them will allow us to create a new framework with which to assess and understand the professional behaviour we expect in medical students, residents and practising doctors.

Contributors: all authors made substantial contributions to conception and design of the study, and acquisition, analysis and interpretation of the data. All authors participated in drafting and revising the article and approved the final version.

Acknowledgements: the authors appreciate the assistance and advice of Drs Cyril Grum, Joyce Wahr and James Woolliscroft.

Funding: this research was supported by the Greenwall Foundation of New York.

Conflicts of interest: none.

Ethical approval: this study was considered exempt by the Medical IRB of the University of Michigan.

\section{REFERENCES}

1 Peabody FW. The care of the patient. JAMA 1927;88:877-82.

2 Huff KL, Koenig JA, Treptau MM, Sireci SG. Validity of MCAT scores for predicting clerkship performance of medical students grouped by sex and ethnicity. Acad Med 1999;74 (Suppl):41-4.

3 Swanson DB, Case SM, Koenig J, Killian CD. Preliminary study of the accuracies of the old and new medical college admission tests for predicting performance on USMLE Step 1. Acad Med 1996;71 (Suppl):25-7.

4 Association of American Medical Colleges. Learning Objectives for Medical Education. http://www.aamc. org/meded/msop/msopl.pdf. [Accessed September 29, 2003.] 
5 General Medical Council. Good Medical Practice. http://www.gmc-uk.org/med_ed/default.htm.

[Accessed September 29, 2003.]

6 Cruess SR, Cruess RL. Professionalism must be taught. BMJ 1997;315:1674-7.

7 Ginsburg S, Regehr G, Hatala R, McNaughton N, Frohna A, Hodges B, Lingard L, Stern DT. Context, conflict, and resolution: a new conceptual framework for evaluating professionalism. Acad Med 2000;75:S6S11.

8 Epstein RM, Hundert EM. Defining and assessing professional competence. JAMA 2002;287:226-35.

9 Christakis NA. The similarity and frequency of proposals to reform US medical education. Constant concerns. JAMA 1995;274 (9):706-11.

10 Fox R. Training in caring competence: the perennial problem in North American medical education. In: Hendrie HC, Lloyd C, eds. Educating Competent and Humane Physicians. Bloomington, Indiana: Indiana University Press 1990;199-216.

11 General Medical Council. Tomorrow's Doctors: Recommendations on Undergraduate Medical Education. http://www.gmc-uk.org/med_ed/default.htm. [Accessed September 29, 2003.]

12 American Board of Internal Medicine, ACP-ASIM Foundation and the European Federation of Internal Medicine. Charter on Professionalism. Ann Intern Med 2002;136:243-6.

13 Stern D. Practising what we preach? An analysis of the curriculum of values in medical education. Am J Med 1998;104:569-75.

14 Stewart JB. Blind Eye: How the Medical Establishment let a Doctor get away with Murder. New York: Simon and Schuster 1999.

15 Anonymous. Doctors in the dock. The Economist. London: February 3, 2001;358:24.
16 Benor DE, Notzer N, Sheehan TJ, Norman GR. Moral reasoning as a criterion for admission to medical school. Med Educ 1984;18 (6):423-8.

17 David H, Nicholaou T. A comparison of the interviewing skills of first and final year medical students. Med Educ 1992;26:441-7.

18 Prislin MD, Lie D, Shapiro J, Boker J, Radecki S. Using standardised patients to assess medical students' professionalism. Acad Med 2001;76:S90-S92.

19 Self D, Olivarez M, Baldwin D Jr. Clarifying the relationship of medical education and moral development. Acad Med 1998;73:517-20.

20 Self DJ, Olivarez M, Baldwin DC Jr. The amount of small group, case study discussion needed to improve moral reasoning skills of medical students. Acad Med 1998;73:521-3.

21 University of Michigan Medical School. Admissions. 2003 http://www.med.umich.edu/medschool/students/admissions.html. [Accessed September 29, 2003.]

22 Edwards JC, Elam CL, Wagoner NE. An admission model for medical schools. Acad Med 2001;76:1207-12.

23 Wright N, Tanner MS. Medical students' compliance with simple administrative tasks and success in final examinations: retrospective cohort study. $B M J$ 2002;324:1554-5.

24 Gordon MJ. A review of the validity and accuracy of self-assessments in health professional training. Acad Med 1991;66:762-9.

25 Hodges B, Regehr G, Martin D. Difficulties in recognising one's own incompetence: novice physicians who are unskilled and unaware of it. Acad Med 2001;76 (Suppl):87-9.

Received 3 June 2003; editorial comments to authors 9 July 2003, 19 January 2004; accepted for publication 22 June 2004 